\title{
El enfoque de la prensa española durante la crisis del Covid-19. Un análisis del framing a través de las portadas de los principales diarios de tirada nacional
}

The Spanish press approach throughout the COVID-19 crisis. An analysis of framing through the front pages of the main national newspapers

Patricia Núñez-Gómez. Universidad Complutense de Madrid. España. pnunezgo@ucm.es

[CV] $\mathrm{G} \mathrm{R}^{\mathrm{O}} \mathrm{O}$

Natalia Abuín-Vences. Universidad Complutense de Madrid. España. nabuinve@ucm.es

[CV] $\mathrm{G} \mathrm{R}^{\mathrm{C}} \mathrm{O}$

Javier Sierra-Sánchez. Universidad Complutense de Madrid. España. javiersierrasanchez@pdi.ucm.es

$[\mathrm{CV}]$ (c) $\mathrm{R}^{\mathrm{g}} \mathrm{O}$

Luis Mañas-Viniegra. Universidad Complutense de Madrid. España.

lmanas@ucm.es

$[\mathrm{CV}]$ G $\mathrm{C}$

Cómo citar este artículo / Referencia normalizada

Núñez-Gómez, P.; Abuín-Vences, N.; Sierra-Sánchez, J. y Mañas-Viniegra, L. (2020). El enfoque de la prensa española durante la crisis del Covid-19. Un análisis del framing a través de las portadas de los principales diarios de tirada nacional. Revista Latina de Comunicación Social, 78, 41-63. https://www.doi.org/10.4185/RLCS-2020-1468

\section{RESUMEN}

Introducción: En este trabajo se lleva a cabo un análisis de las portadas de los principales diarios españoles durante la crisis del Covid-19. Metodología: El objetivo principal de este estudio es analizar el enfoque o framing empleado por las diferentes cabeceras para trasladar la información sobre la pandemia y su impacto a la sociedad. La metodología empleada fue el análisis de contenido de las portadas de la prensa española. El diseño de la muestra se ha basado en tres criterios: temporal, profesional y discursivo. Resultados/Discusión: El tono empleado por las principales cabeceras en sus titulares de portada fue negativo. Esta negatividad se centra en la gestión que de esta crisis está realizando el Gobierno. Los principales temas han sido sanidad, política y economía. En cuanto al tratamiento visual, las cabeceras han resaltado en sus fotografías a la sociedad civil como actor informativo por delante de políticos o instituciones oficiales. Conclusiones: El actor institucional 
más presente en el análisis discursivo de los titulares ha sido el Gobierno, representado en la figura de su Presidente.

PALABRAS CLAVE: Covid-19; coronavirus; crisis sanitaria; framing; agenda setting; noticias; periódicos.

\begin{abstract}
Introduction: In this work, an analysis of the front pages of the main Spanish newspapers during the Covid-19 crisis is carried out. Methodology: This study's main objective is to analyze the approach or framing adopted by the various headers to convey information regarding the pandemic and its impact on society. For this purpose, the methodology applied consisted of analyzing the cover pages' contents in the Spanish press. The sample design has been based on three criteria: temporal, professional and discursive. Results/Discussion: The tone of the main headlines on the front pages was negative. Such negativity focuses on the government's management of this crisis. Similarly, the topics covered in the headline condition the tone. The following have been the main topics, in this order: health, politics and economy. In terms of visual treatment, it should be noted that the headlines have highlighted civil society in their photographs as an information actor ahead of politicians and official institutions. Conclusions: The most present institutional actor in the headlines' discursive analysis has been the Government represented in the figure of its President.
\end{abstract}

KEYWORDS: Covid-19; coronavirus; health crisis; framing; agenda setting; news; newspapers.

\title{
CONTENIDO
}

1. Introducción. 2. Objetivos. 3. Metodología. 4. Resultados / Discusión. 5. Conclusiones. 6. Bibliografía 7. Currículum Vitae

\section{Introducción}

Desde 1995, se han producido seis brotes que la Organización Mundial de la Salud (OMS) ha calificado como emergencias de salud internacionales, según el Reglamento Sanitario Internacional (RSI) revisado en 2005: la Gripe H1N1, la Polio, el Ébola en África occidental y en la República Democrática del Congo, el Zika y, ahora, el Covid-19. Otros dos coronavirus, el SARS y el MERS, también se extendieron internacionalmente, aunque no fueron considerados emergencia sanitaria internacional (Ratzan, Gostin, Meshkti, Rabin y Parker, 2020).

El año 2020 comenzó con la noticia de que un desconocido virus respiratorio, denominado Covid-19, había sido detectado en la ciudad China de Wuhan. Las primeras noticias sobre esta crisis sanitaria llegaron a España la segunda semana de enero, aunque hasta el 31 de enero no se documentó el primer contagio en España, un turista alemán que había estado en contacto con un ciudadano chino y que se encontraba aislado en la isla de La Gomera. Los primeros casos peninsulares se verificaron el 24 de febrero en la Comunidad de Madrid, Cataluña y la Comunidad Valenciana. A partir de este momento, se multiplicó de forma exponencial el número de infectados y el Gobierno de España decretó el Estado de Alarma el 14 de marzo, que fue prorrogado sucesivamente (Costa-Sánchez y López-García, 2020).

Esta última emergencia de salud mundial ha dado como resultado una respuesta política y social sin precedentes y ya está teniendo consecuencias masivas en la economía global. La avalancha de la respuesta humana se ha facilitado por el flujo de información, canalizado tanto a través de los medios de masas tradicionales como de las redes sociales (Singh et al., 2020). 
Numerosos estudios de caso sobre la comunicación del riesgo de crisis han señalado que el público suele malinterpretar los mensajes, las advertencias no funcionan, se generan falsos rumores, determinadas fuentes brindan información inconsistente, las poblaciones no muestran tranquilidad y los medios tratan la historia de manera sensacionalista (Glik, 2007). Sin embargo, la comunicación del riesgo de crisis es esencial para salvar vidas y desempeña un papel fundamental en los esfuerzos de mitigación de desastres. En efecto, cuando una crisis sanitaria se prolonga, los medios y la ciudadanía pierden la paciencia. En estos casos, los dedos acusatorios comienzan a apuntar a aquellos que ostentan la autoridad y el pánico suele dejar paso al enfado colectivo (Garrett, 2001).

Gestionar una pandemia como la del Covid-19 requiere un enfoque equilibrado que transmita a los ciudadanos lo que ellos y el sistema de salud pueden hacer sin provocar pánico (Cowper, 2020). Sin embargo, Cowper apunta a que China, país en el que se originó del virus, utilizó un enfoque autoritario para minimizar la gravedad del brote en sus primeras etapas, por lo que es paradójico que su postura sobre el cierre de ciudades se haya perfilado también como una medida eficaz para frenar el virus en los países europeos. Según lo previsto ya en 2017 por un informe del World Economic Forum, los riesgos globales están interconectados. En particular, el caso de la epidemia de Covid-19 está mostrando el papel fundamental de la difusión de información en un ciclo de noticias que, en muchos casos, carece de intermediario (Cinelli et al., 2020).

La rápida escalada del virus se ha asociado con una comunicación confusa y, a veces, contradictoria, sobre su propagación. Por ello, para los medios está siendo un desafío informar sobre el estado del brote a medida que la información está disponible en momentos y de maneras impredecibles (Ratzan, Gostin, Meshkti, Rabin y Parker, 2020). El único bastión de defensa contra el creciente pánico de la ciudadanía, la histeria del mercado financiero y los malentendidos no intencionados de la ciencia y la epidemiología del Covid-19 es una contra-información ágil, precisa y disponible en todo el mundo que transmita una narrativa basada constantemente en la ciencia. Esta pandemia presenta mecanismos de entrega de información científica sin precedentes, aumentando la presión para una adecuada interpretación por parte de los medios y la ciudadanía (Garrett, 2020).

Es indudable que la crisis sanitaria en los medios se ha convertido desde su irrupción en el tema central de sus agendas, copando las portadas y la mayor parte del espacio informativo, tanto de los medios de comunicación de masas tradicionales como de los digitales. Por ello, tomando como base los trabajos precedentes y las teorías sobre los efectos cognitivos de los medios en la opinión pública, es necesario potenciar una investigación rigurosa sobre el tratamiento informativo de un tema, en este caso, la pandemia derivada de la expansión de Covid-19 en los medios de comunicación desde las teorías de la agenda setting y el encuadre o framing.

\subsection{Las teorías de la agenda setting y el framing}

Las teorías de la agenda setting y del framing tienen como punto de convergencia la estructura y contenido de las informaciones publicadas por los medios. Esta teoría fue planteada por McCombs y Shaw (1972) y se basa en la idea de Cohen (1964) sobre cómo los medios de comunicación no indican tanto en qué pensar, sino sobre qué pensar. Los conocimientos que adquieren los ciudadanos sobre determinados fenómenos -el Covid-19, en este caso- no se deben a la experiencia directa o conocimiento profundo de los mismos, sino más bien son los medios de comunicación los que actúan estableciendo una lista de temas relevantes.

Este hecho influye condicionando a los actores a la realidad social de su entorno. Por consiguiente, los medios de comunicación tienen la capacidad de dirigir la mirada de gran parte de los ciudadanos hacia unos temas u otros. La información que ponen a disposición de los ciudadanos los medios de 
comunicación no es responsabilidad única de éstos. Rogers y Dearing (1994, p.79) indicaron que la información a la que se expone la opinión pública procede de la confluencia de tres agendas: la de los medios de comunicación, la pública y la política. Estas agendas hacen referencia a los asuntos o temas que los medios de comunicación, los agentes políticos y la opinión pública consideran más relevantes dentro de un contexto espacio-temporal concreto. Por lo tanto, se plantea que la cobertura y atención periodística influyen en las prioridades y preocupaciones de los ciudadanos.

La teoría del framing en los medios de comunicación surge en la década de los sesenta y se consolida en los ochenta, cuando los análisis de los efectos de los medios se vinculan con cuestiones de tipo cognitivo, como sucede con los trabajos sobre la agenda setting. La premisa principal de la teoría del framing es que un fenómeno puede verse desde una variedad de perspectivas y puede interpretarse desde múltiples valores o consideraciones. El framing se refiere al proceso mediante el cual las personas despliegan una conceptualización particular de una cuestión o reorientan su pensamiento sobre un tema (Chong y Druckman, 2007). Sábada-Garraza ya advirtió (2004, p.2) que el framing tiene un componente relevante de enfoque particular, ya que los hechos serán dispuestos por el periodista desde un enfoque determinado por influencias personales y profesionales (Masip et al., 2020), dejando a un lado fenómenos como la desinformación o los bulos (Salaverría et al., 2020).

La aplicación del framing en la investigación en Comunicación cuenta ya con una sólida trayectoria, que posibilita considerarlo como uno de los conceptos clave en esta área de conocimiento (VicenteMariño y López-Rabadán, 2009).

Desde el punto de vista de los medios de comunicación, un frame sirve para organizar la realidad cotidiana (Tuchman, 1978) al proporcionar significado a una serie de eventos que se están produciendo (Gamson y Modigliani, 1989) y promover definiciones e interpretaciones particulares sobre temas políticos (Shah, Watts, Domke y Fan, 2002). Es decir, supone seleccionar, enfatizar y estructurar paquetes de información para fijar una perspectiva desde la que interpretar un tema (Fenoll y Rodríguez-Ballesteros, 2017).

Pero, ¿cuál es el vínculo entre la agenda setting y la teoría del framing? Hay una corriente mayoritaria entre los investigadores en Comunicación que considera que las dos teorías (framing y agenda-setting) son complementarias, pero autónomas (Ardèvol-Abreu, 2015). McCombs, Llamas, López-Escobar y Rey (1997) equiparan el framing con el segundo nivel de la agenda setting. Estos autores sugieren que en el lenguaje del segundo nivel de configuración de la agenda, el frame, es la selección de un número restringido de atributos temáticamente relacionados para su inclusión en la agenda de los medios cuando se discute un objeto en particular. Argumentan que hay muchas otras agendas de atributos y que se necesita un buen mapa teórico para poner orden en los tipos de marcos discutidos en otros trabajos.

Weaver (2007) también reconoce que hay similitudes entre el framing y el segundo nivel de la agenda setting. Ambos están más preocupados por la forma en que los problemas u otros objetos (personas, grupos, organizaciones, países, etc.) se representan en los medios de comunicación que por los problemas u objetos sobre los que se informa de manera más o menos prominente. Ambos se centran en los aspectos más destacados, temas o descripciones de los objetos de interés y se preocupan por las formas de pensar más que por los objetos de pensamiento. Pero el frame parece concentrar una gama más amplia de procesos cognitivos, tales como evaluaciones morales, razonamientos causales, apelaciones a principios y recomendaciones para el tratamiento de problemas que el establecimiento de la agenda de segundo nivel (la importancia de los atributos de un objeto). 
La teoría del framing aplicada a la Comunicación se inscribe en la teoría de la mediación informativa. Los medios, por tanto, desempeñan un papel de intermediarios entre los ciudadanos y el mundo que les rodea. En esa tarea, los medios otorgan a las noticias un enfoque o cuadro determinado (frame), entendiendo por encuadre la idea central organizadora del contenido de las noticias que aporta un contexto mediante un proceso de selección, énfasis, exclusión y elaboración.

\subsection{La teoría del framing aplicada a las crisis sanitarias}

Los medios de comunicación constituyen el principal foco de atención sobre las controversias y los problemas científicos, llamando la atención de los responsables políticos, los grupos de interés y el público. Los medios no solo influyen en la atención de los actores políticos y los ciudadanos, sino que también intervienen en cómo se definen, simbolizan y resuelven en última instancia los problemas relacionados con la ciencia y la tecnología (Nisbet, Brossard y Kroepsch, 2003). Los medios de comunicación son, en sí mismos, una organización política, tienen contacto directo con los responsables políticos, seleccionan una variedad de posibles noticias y fuentes, llevando a menudo a los actores políticos hacia acciones que anticipan la agenda y la naturaleza de las noticias (Cook, 1998).

Los problemas que reciben la mayor atención de los medios son aquellos que se dramatizan o narran con mayor facilidad. Estas noticias dramáticas enfatizan la crisis, el suceso individual en el pasado o el futuro, y los conflictos entre personalidades (Nisbet, Brossard y Kroepsch, 2003). McCombs y Shanahan (1999) mostraron que la cobertura de un problema comienza con un incremento de reclamos dramáticos que atrae la atención sobre el problema, alcanza un pico en la cobertura con los esfuerzos para resolverlo y luego disminuye durante el desenlace y la resolución del mismo.

Estos aspectos se vuelven más relevantes cuando los eventos y acontecimientos científicos entrañan riesgos para la salud. En estas situaciones, el enfoque de los medios es fundamental para informar adecuadamente al público, evitar que cunda el pánico y promover las medidas de prevención indicadas por las autoridades sanitarias.

Singh et al. (2020) realizaron una investigación sobre el enfoque de las epidemias en los medios impresos e identificaron seis tipos de frames:

- Consecuencia. Pone el foco en las consecuencias de la crisis: vidas humanas, impacto social, económico...

- Incertidumbre. Destaca aspectos desconocidos de la epidemia: cura, expansión...

- Acción. Enfatiza cualquier acción contra la enfermedad: prevención, posibles soluciones, estrategias...

- Seguridad. Minimiza en el público la preocupación por los efectos de la enfermedad. También enfatiza la preparación y/o el éxito de las autoridades para combatirla.

- Conflicto. Se centra en desacuerdos respecto a la epidemia: fuentes novedosas, decisiones para combatirla...

- Nuevas evidencias. Aporta datos inéditos sobre la enfermedad.

Mediante una comparación de los frames usados por el New York Times en la cobertura de tres epidemias (la enfermedad de las vacas locas, el virus del Nilo Occidental y la gripe aviar), estos autores concluyeron que, aunque los periodistas enfatizaron las consecuencias y los marcos de acción consistentemente en todas las enfermedades, también tuvieron en cuenta la especificidad de cada enfermedad al diferenciar niveles de importancia en otros frames en relación con el riesgo de la epidemia en cuestión. Además de mostrar que las consideraciones narrativas varían según las enfermedades, también encontraron que estos temas narrativos cambian según la fase en la que se encuentre el desarrollo de la epidemia. Este trabajo también arrojó luz sobre el vínculo entre los frames y la naturaleza de un problema, de modo que cuanto más político era un problema, más 
destacado era el frame del conflicto en la cobertura de los medios. El tratamiento de la enfermedad de las vacas locas, que estuvo teñida de tintes políticos, contenía más marcos de conflicto que el de las otras dos enfermedades.

Wallis y Nerlich (2005) llevaron a cabo una investigación sobre el frame metafórico y la cobertura mediática del SARS en Reino Unido, cuyo tratamiento reflejaba algunas propiedades del enfoque de los problemas globales. El SARS destacó el papel de las organizaciones internacionales que impulsaban novedosas agendas sobre algunos problemas globales. En la situación geopolítica de aquel entonces, pocas instituciones podían reclamar un papel real de dirección o poseer activos significativos de su propiedad, además de los gobiernos nacionales. Funcionaron como organismos asesores, reguladores y de coordinación y dependían de la buena voluntad de los gobiernos nacionales para hacer cumplir sus propósitos. Esto, a su vez, afectó al frame metafórico de los problemas internacionales e indujo el enfoque burocrático y gerencial que se puede ver en el discurso de SARS en lugar de otros sistemas de metáfora de guerra. Comprender este cambio en el frame, lejos del bien establecido sistema metafórico de la guerra y las plagas, podría no solo señalar un cambio en la percepción y la vigilancia de una enfermedad emergente, sino también contribuir a un cambio en la teoría de la metáfora misma, lejos de verla como un dispositivo puramente retórico o cognitivo para ver uno cultural y político.

Tian y Stewart (2005) compararon el frame utilizado por la BBC y la CNN durante la crisis del SARS, concluyendo que ambas se centraron en el brote y sus efectos sobre la salud pública y el sistema médico, y enmarcaron el problema desde una perspectiva global. La OMS desempeñó un papel clave en ambos medios y la salud pública en todo el mundo fue una preocupación común. Sin embargo, la dimensión económica de esta crisis fue más prominente en las noticias de la CNN que en las de la BBC. Esto puede sugerir una diferencia cultural sobre la enfermedad como un fenómeno social, médico y económico.

Estos frames están directamente relacionados con la capacidad de persuasión que las fuentes informativas tienen en función de su credibilidad y atractivo (McGuire, 1985). En lo tocante a esta segunda cualidad, las fuentes más atractivas a los ojos de la audiencia poseen un mayor poder persuasivo. En primer lugar, porque una fuente atractiva puede determinar que se le preste atención al mensaje, mientras que otra menos atractiva quizá no evite pasar desapercibida. En segundo lugar, el atractivo de la fuente puede influir en la fase de aceptación, pues el receptor, a través del proceso de identificación, puede querer desear, pensar o actuar de la misma manera que lo hace la fuente. En tercer lugar, el atractivo puede incrementar la credibilidad de la fuente. De ahí que, en un sector tan competitivo como el de la prensa, se trate cada día de elaborar la presentación más llamativa posible para el lector. Esa llamada de atención viene determinada por la composición de los textos (en forma de titulares, fotografías y elementos gráficos). Vander-Zanden (1986, p.222), desde la Psicología Social, define la persuasión como "un intento deliberado de una persona o grupo de personas, de influir en las actitudes o conductas de otros, con el objeto de alcanzar algún fin preestablecido". Para que exista persuasión es necesario que el emisor de la información goce de cierta credibilidad, así como que el mensaje resulte exacto y apropiado sobre el conocimiento preexistente que posee el receptor Álvarez-Gálvez (2012, p.5). Asimismo, la ciudadanía está acomodada a este tipo de fuente de información (León et al., 2018).

En definitiva, tanto en la agenda setting como en la teoría del framing se toman decisiones, se recoge o se omite información, se resaltan o se ignoran asuntos, se escriben titulares para atraer la atención y se incorpora material gráfico para ilustrar los temas. Se establecen, por tanto, prioridades temáticas cuyo éxito depende de la credibilidad y el atractivo de la fuente. En cada uno de esos pasos, se perfila el encuadre. 


\section{Objetivos}

A partir de una investigación longitudinal del análisis de las portadas de los diarios de información general de tirada nacional en España, el objetivo general de este trabajo es determinar el enfoque adoptado por estos medios ante la pandemia provocada por el Covid-19.

Los objetivos específicos son:

- Examinar los titulares principales de las portadas con el objeto de conocer en profundidad a qué temas y qué finalidad (tono) presentan.

- Estudiar el actor y el espacio informativo del titular para descubrir qué tipología tiene más presencia en esta pandemia.

- Realizar un análisis fotográfico de las portadas con el fin de descubrir el enfoque visual de las mismas.

- Determinar el grado de homogeneidad de la agenda mediática de portada, cuantificando el nivel de coincidencia en el tema principal de portada entre los periódicos examinados e identificando las semejanzas y diferencias entre sus agendas de temas, actores y espacios.

- Llevar a cabo un análisis discursivo de los titulares para establecer posicionamientos.

- Definir la realidad proyectada por la prensa generalista para establecer la taxonomía del encuadre temático de cada uno de los medios objeto de estudio.

\section{Metodología}

El método utilizado ha sido el análisis de contenido de las portadas de los diarios generalistas en papel más significativos de la prensa española. El análisis de las portadas de los diarios ha sido objeto de investigación (Erbring, Goldenberg y Miller,1980; Danielson y Lasorsa, 1997; DavaraTorrego, López-Raso, Martínez-Fresneda y Sánchez-Rodríguez, 2004; Alvarado, 2008; Gibson, 2011) y posibilita reconocer en una sola imagen el carácter estratégico que en ese apartado vuelcan las empresas periodísticas. Es ahí donde se vislumbra, de forma más o menos explícita, la línea editorial y desempeñan un papel crucial en los encuadres interpretativos (Scheufele y Tewksbury, 2007; Vicente-Mariño y López-Rabadán, 2009; López-Rabadán, 2010), cuyo análisis longitudinal parte "de la relevancia social y democrática de la información, de la importancia periodística de la portada y de la vinculación con el desarrollo actual de los estudios de agenda setting" (LópezRabadán y Casero-Ripollés, 2012, p.472).

De ahí que se plantee el análisis de las mismas como una forma de conocer el enfoque que cada cabecera ha otorgado a la pandemia del Covid-19 con respecto a otras noticias que están aconteciendo. Esta investigación se centra en cómo las portadas plasman a nivel textual y gráfico el día a día de este virus en los 30 días de su fase más crítica, en la que la evolución de muertos por causa de ese virus ha alcanzado en España la cifra de $21.717^{1}$ muertos.

Se han identificado una serie de variables (Tabla 1) adaptando el modelo planteado por LópezRabadán y Casero-Ripollés (2010, p.476). Del mismo modo, ha sido necesario un análisis categorial dentro del tema, así como de encuadre (Bardin, 1986; Entman, 1993; Gamson y Modigliani, 1989; Scheufele, 1999). También se desea conocer el tono o dirección de los titulares. Se codificó el titular destacado de portada con predominio de frases positivas, negativas o neutras sobre la pandemia del Covid-19 (Bardin, 1986; García-Ferrando, Ibáñez y Alvira, 1986; López-Aranguren, 1989; Piñuel y Gaitán, 1995). Por otro lado, el trabajo de Tankard (2001) ha servido para adaptar el análisis de contenido a fotografías y material ilustrativo.

${ }^{1}$ Número de fallecidos a 22/04/2020, según Ministerio de Sanidad. 
El diseño de la muestra se ha basado en tres criterios: temporal, profesional y discursivo. Referente al primero, se han determinado las fechas en las que el Covid-19 estaba empezando a atraer el interés mediático hasta la fase de máxima mortandad. Con respecto al criterio profesional, se han seleccionado los diarios españoles generalistas de mayor difusión en el territorio nacional. Además, se ha buscado la diversidad política que tradicionalmente presentan estos medios para que el estudio ofrezca una mayor riqueza de datos y consolidación de estos. Y, por último, en lo referido al discurso se ha centrado el análisis exclusivamente en la noticia más relevante de la portada, es decir, el tema principal de cada edición de los diarios estudiados. También ha sido objeto de análisis la fotografía principal de portada de cada diario.

Tabla 1. Valores asociados a las variables de análisis.

\begin{tabular}{|c|c|c|}
\hline Variables & \multicolumn{2}{|c|}{ Valores asociados } \\
\hline Tema principal & $\begin{array}{ll}\text { 1. } & \text { Política } \\
\text { 2. } & \text { Economía } \\
\text { 3. } & \text { Empleo } \\
\text { 4. } & \text { Internacional } \\
\text { 5. } & \text { Sanidad } \\
\text { 6. } & \text { Educación } \\
\text { 7. } & \text { Unión Europea } \\
\text { 8. } & \text { Medio Ambiente } \\
\text { 9. } & \text { Energía } \\
\text { 10. } & \text { Deportes } \\
\text { 11. } & \text { Industria } \\
\text { 12. } & \text { Bienestar social } \\
\end{array}$ & $\begin{array}{l}\text { 13. Corrupción } \\
\text { 14. Elecciones } \\
\text { 15. Agricultura } \\
\text { 16. Cultura } \\
\text { 17. Inmigración } \\
\text { 18. Terrorismo } \\
\text { 19. Vivienda } \\
\text { 20. Monarquía, Casa Real } \\
\text { 21. Organización territorial del } \\
\text { Estado } \\
\text { 22. Poder Judicial } \\
\text { 23. Otros }\end{array}$ \\
\hline Actor informativo & $\begin{array}{ll}\text { 1. } & \text { Instituciones/oficiales } \\
\text { 2. } & \text { Políticos } \\
\text { 3. } & \text { Económicos } \\
\text { 4. } & \text { Alternativos } \\
\text { 5. } & \text { Sociedad civil }\end{array}$ & $\begin{array}{ll}6 . & \text { Sistema de medios de } \\
& \text { comunicación } \\
\text { 7. } & \text { Culturales } \\
\text { 8. } & \text { Otros }\end{array}$ \\
\hline Espacio informativo & $\begin{array}{ll}\text { 1. } & \text { España (nacional/ } \\
& \text { autonómico/local) } \\
\text { 2. } & \text { Referencia global/mundial } \\
\text { 3. } & \text { Estados Unidos } \\
\text { 4. } & \text { Unión Europea } \\
\text { 5. } & \text { Resto de Europa } \\
\end{array}$ & $\begin{array}{ll}6 . & \text { Rusia } \\
\text { 7. } & \text { Asia } \\
\text { 8. } & \text { América Latina } \\
\text { 9. } & \text { Oriente medio y Magreb } \\
\text { 10. África Subsahariana } \\
\text { 11. } \\
\end{array}$ \\
\hline Fotografía & $\begin{array}{l}\text { 1. Con personaje político } \\
\text { 2. Sin personaje político }\end{array}$ & \\
\hline Tono del titular & $\begin{array}{ll}\text { 1. } & \text { Positivo } \\
\text { 2. } & \text { Neutro } \\
\text { 3. } & \text { Negativo }\end{array}$ & \\
\hline
\end{tabular}

Fuente: Adaptado de López-Rabadán y Casero-Ripollés (2012).

La muestra de análisis (Tabla 2) estuvo formada por los seis principales diarios nacionales de información general a partir de los últimos datos de difusión (marzo de 2020) y de audiencias ( $1^{\text {a }}$ Ola de 2020) accesibles. 
Tabla 2. Difusión y número de lectores de los diarios de tirada nacional en España.

\begin{tabular}{|c|c|c|}
\hline Periódico & Difusión & Lectores (000) \\
\hline El País & 92.633 & 1.004 \\
\hline La Vanguardia & 83.870 & 532 \\
\hline El Mundo & 70.230 & 657 \\
\hline ABC & 65.074 & 444 \\
\hline El Periódico & 50.057 & 362 \\
\hline La Razón & 40.353 & 194 \\
\hline
\end{tabular}

Fuente: OJD y AIMC (2020).

El análisis de contenido se realizó durante la primera quincena de abril de 2020 a partir de las portadas diarias en papel de los 6 periódicos que integran la muestra durante un intervalo de 30 días $(\mathrm{n}=180)$ desde el inicio de la crisis del coronavirus Covid-19 en España ( 7 de marzo al 5 de abril). El análisis cualitativo se realizó con el software Atlas.ti v. 8.4.4, mientras que para el análisis estadístico se utilizó SPSS v.22.

\section{Discusión / Resultados}

El $49,8 \%$ del total de las portadas destacaron por un tono del titular negativo (Figura 1), frente al $28,3 \%$ neutro y un 22,2\% positivo. Considerando los sentimientos de temor, preocupación (Ahorsu, Lin, Imani, Saffari, Griffiths y Pakpour, 2020), ansiedad, depresión (Stein, 2020), insomnio o ira (Torales, O'Higgins, Castaldelli-Maia y Ventriglio, 2020) que ha despertado el coronavirus Covid-19 en las personas de todo el mundo, parece coherente que el framing de las portadas de los periódicos nacionales se haya orientado hacia una visión más catastrofista que optimista, en un escenario crítico en el que ha primado la incertidumbre (Brown, 2020). El miedo y la estigmatización de los infectados por el virus han sido constantes en esta crisis sanitaria, como ya ocurrió anteriormente con el SARS y el MERS (Li et al., 2020).

La tabla cruzada entre las variables Periódico y Tono del titular presentó una relación leve entre ambas, con un Coeficiente de Contingencia de 0,279 y una diferencia que no fue estadísticamente significativa $(p=0,124)$, por lo que no se produce una relación de dependencia entre estas variables. La Razón $(63,3 \%)$, ABC $(56,7 \%)$ y El Mundo $(53,3 \%)$ fueron los diarios con un mayor porcentaje de portadas con tono negativo, mientras que, paradójicamente, $\mathrm{ABC}(26,7 \%)$ y El Mundo (30,0\%) fueron también los dos periódicos que publicaron más portadas con un tono positivo. Los dos periódicos catalanes de tirada nacional fueron los más neutrales en sus portadas $(50,0 \% \mathrm{La}$ Vanguardia y 33,3\% El Periódico). 


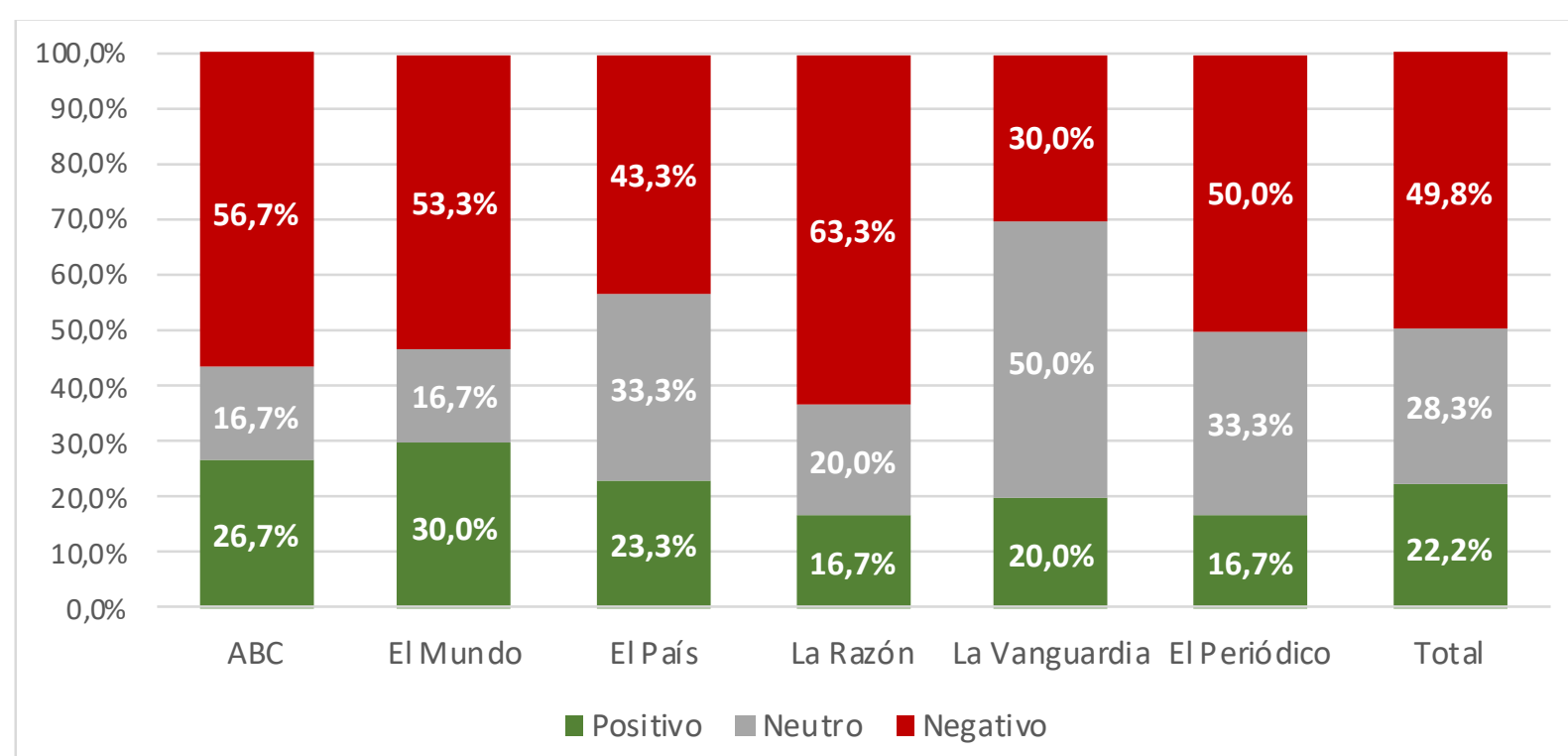

Figura 1: Tono del titular por periódico $(\mathrm{n}=180)$.

Fuente: Elaboración propia.

Al contrario de lo que sucedía con la cabecera del periódico, los temas recogidos por el titular sí condicionan el tipo de tono empleado de manera significativa $(p=0,020)$. Cuando el tema del titular fue Cultura, el tono siempre fue positivo $(100,0 \%)$ y cuando fue Bienestar Social, el tono positivo fue mayoritario (66,7\%). Sin embargo, Poder Judicial (100,0\%) y Empleo (90,9\%) fueron temas vinculados a un tono negativo.

En el análisis cruzado de las variables Fecha de las portadas y Tono del titular (Tabla 3), dada la amplitud de los 30 días observados, existieron diferencias significativas y, por tanto, una relación de dependencia $(p=0,014)$. En el análisis de determinadas fechas clave, se aprecia cómo ha ido evolucionando la posición de los periódicos, considerando que las fechas indicadas se corresponden con las de publicación, es decir, se refieren a acontecimientos acaecidos el día anterior. Cuando el 7 de marzo se decretó la cuarentena para un grupo numeroso de Haro que propagó el Covid-19 en un funeral, el tono empleado fue mayoritariamente neutro $(66,7 \%)$ y negativo $(33,3 \%)$ y al siguiente día, cuando Sanidad desaconsejó el día previo a la manifestación feminista del 8-M la asistencia a actos masivos para quien tuviese algún síntoma respiratorio, el tono se repartió por igual entre positivo, neutro y negativo (33,3\% en cada caso), lo cual refleja ya los puntos de vista sobre una polémica con defensores y detractores que ha sido utilizada durante toda la crisis del Covid-19 para alertar sobre las decisiones erróneas del Gobierno y, en otros casos, para intentar volcar parte de la responsabilidad de la crisis sanitaria en el feminismo.

Los días siguientes, cuando cambia el discurso del Gobierno sobre la gravedad de la situación sanitaria, desaparece el tono positivo $(0,0 \%)$ y se convierte mayoritariamente en negativo en el titular sobre la manifestación feminista publicado el 9 de marzo $(66,7 \%$ negativo), el titular sobre el cierre de los centros educativos decretado por Madrid el 10 de marzo (66,7\% negativo) y la declaración de la pandemia por parte de la Organización Mundial de la Salud y el inicio del cierre de centros escolares el 12 de marzo (50\% negativo).

Parece que es en este momento en el que se empiezan a tomar decisiones restrictivas cuando los periódicos empiezan a publicar titulares positivos de nuevo. Así, el 15 de marzo se decreta el Estado de Alarma (16,7\% positivo), el 29 de marzo lo endurece (33,3\% positivo) y el 4 de abril anuncia una 
segunda prórroga (33,3\% positivo y $0,0 \%$ negativo). Por tanto, parece que la toma de conciencia sobre la gravedad de la crisis sanitaria lleva a que las medidas que podrían ser consideradas negativamente por la población se convierten en neutras e, incluso, positivas para los medios de comunicación, que adoptan su función formativa e informativa de un modo responsable. El hecho de que las acciones que se toman contra el virus centren la atención de los medios, recalca la aparición del frame de Acción detectado por Singh et al. (2020) en su investigación sobre el enfoque de las epidemias en los medios impresos. Así mismo, estos datos confirman que la cobertura de una crisis comienza con un incremento de reclamos dramáticos que atrae la atención sobre el asunto, alcanza un pico en la cobertura con los esfuerzos para resolverlo y luego disminuye durante el desenlace y la resolución del mismo (McCombs y Shanahan, 1999).

Esta cuestión es más clara al contemplar que, durante los días 15 y 23 de marzo, los titulares sobre el Estado de Alarma presentan un Tema del titular Político (83,3\% en ambas fechas), mientras que el 29 de marzo el Tema es principalmente Económico (50,0\%) por las consecuencias del endurecimiento del Estado de Alarma. En el anuncio de la $2^{\text {a }}$ prórroga del Estado de Alarma, en cambio, el Tema del titular pasa a ser mayoritariamente sobre Sanidad $(66,7 \%)$.

Estos resultados también son coherentes con una narrativa en la que es más destacado el frame del Conflicto cuanto más político es el tema (Singh et al., 2020), considerando que las dificultades que se dramatizan son las que reciben la mayor atención de los medios (Nisbet, Brossard y Kroepsch, 2003). Al igual que sucedió con la crisis sanitaria del coronavirus SARS, se afronta como fenómeno social, médico y económico (Tian y Stewart, 2005).

La función formativa queda reforzada también por el análisis del Actor informativo que figura en la fotografía, puesto que en los titulares asociados al cierre de centros educativos $(83,3 \%$, el 10/3 y $50,0 \%$, el 12/3), el decreto del Estado de alarma (66,7\%), el anuncio de la primera prórroga (83,3\%) y el anuncio del endurecimiento del mismo $(66,7 \%)$ destaca la sociedad Civil, en lo que parece un intento de concienciar a la población para que se implique con la medida restrictiva.

Tabla 3. Tabla cruzada Fecha de la Portada/Tono del titular.

\begin{tabular}{|c|c|c|c|c|}
\hline Fecha & Noticia & Positivo & Neutro & Negativo \\
\hline $7 / 3 / 2020$ & Cuarentena en Haro a un grupo que se contagió en un funeral. & $0,0 \%$ & $66,7 \%$ & $33,3 \%$ \\
\hline $8 / 3 / 2020$ & $\begin{array}{c}\text { Sanidad desaconseja asistir a actos masivos a quien tenga tos o } \\
\text { síntomas respiratorios. }\end{array}$ & $33,3 \%$ & $33,3 \%$ & $33,3 \%$ \\
\hline $9 / 3 / 2020$ & Manifestación feminista 8-M. & $0,0 \%$ & $33,3 \%$ & $66,7 \%$ \\
\hline $10 / 3 / 2020$ & Madrid decreta el cierre de los centros educativos. & $0,0 \%$ & $33,3 \%$ & $66,7 \%$ \\
\hline $12 / 3 / 2020$ & La OMS declara la pandemia. Inicio del cierre de centros \\
& educativos. & $0,0 \%$ & $50,0 \%$ & $50,0 \%$ \\
\hline $15 / 3 / 2020$ & El Gobierno decreta el Estado de Alarma. & $16,7 \%$ & $33,3 \%$ & $50,0 \%$ \\
\hline $23 / 3 / 2020$ & El Gobierno anuncia la 1 $1^{\text {a prórroga del Estado de Alarma. }}$ & $0,0 \%$ & $50,0 \%$ & $50,0 \%$ \\
\hline $29 / 3 / 2020$ & El Gobierno decreta el endurecimiento del Estado de Alarma. & $33,3 \%$ & $33,3 \%$ & $33,3 \%$ \\
\hline $4 / 4 / 2020$ & Se anuncia la $2^{a}$ prórroga del Estado de Alarma. & $33,3 \%$ & $66,7 \%$ & $0,0 \%$ \\
\hline
\end{tabular}

Fuente: Elaboración propia.

En otras catástrofes con efectos para la salud también se ha identificado la responsabilidad de los medios en las noticias publicadas, aunque es habitual que difieran en función de la cabecera y el periodo de tiempo considerado (Thomas, Kannaley, Friedman, Tanner, Brandt y Spencer, 2016). Esta orientación es consecuencia del aumento que se produce en la percepción de riesgo cuando hay 
una proximidad alta de una epidemia y por la posible identidad de invulnerabilidad que puede extenderse entre la población más joven (Idoiaga, Gil-de-Montes y Valencia, 2016). Sin embargo, en otras pandemias sanitarias también se ha puesto de manifiesto que son numerosos los periódicos europeos que amplifican de manera sensacionalista los riesgos para enfatizar el conflicto, el drama y la emoción en su cobertura de la noticia (Rossmann, Meyer y Schulz, 2018).

El carácter sanitario que dio origen a la crisis del coronavirus también se refleja en los temas que protagonizaron las portadas de los diarios (Figura 2). De este modo, el 35,0\% de las portadas versaron sobre Sanidad, con un protagonismo destacado de la Política $(26,1 \%)$ y la Economía $(20,6 \%)$. Con una relevancia menor, emergieron temas como el Empleo (6,1\%), Internacional (4,4\%) o Bienestar Social (3,3\%). La Cultura y el Poder Judicial, con una presencia del 0,6\% cada uno, fueron temas irrelevantes durante la crisis del Covid-19.

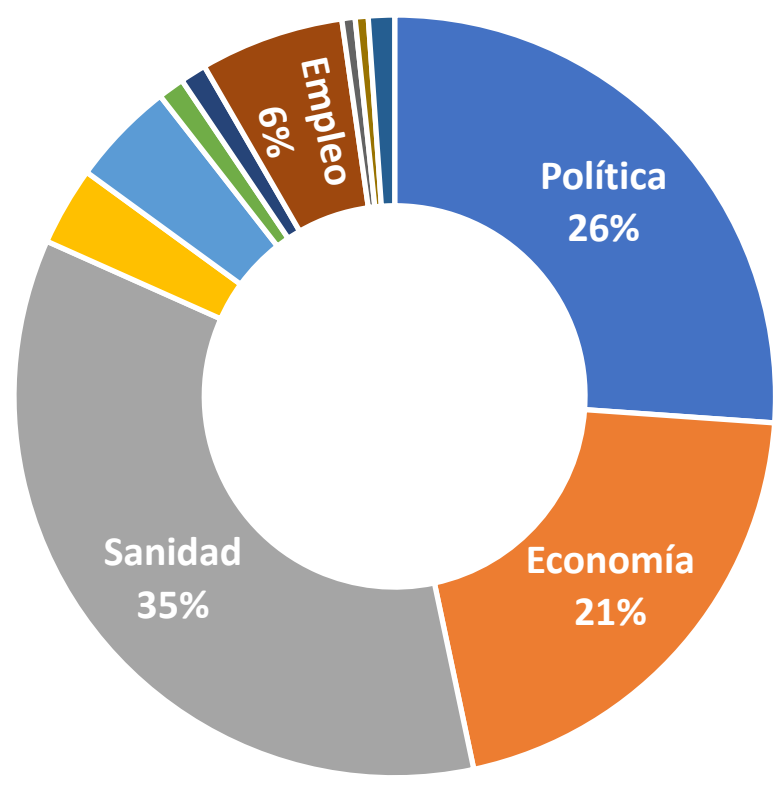

Figura 2: Tema del titular de las portadas de los periódicos $(n=180)$.

Fuente: Elaboración propia.

El cruce de variables entre Periódico y Tema del titular mostró una relación de nivel intermedio, con un coeficiente de contingencia de 0,465 , a pesar de que no existieron diferencias estadísticamente significativas $(p=0,490)$ que permitan concluir una relación de dependencia entre las variables. Pese a ello, el análisis cruzado puso de manifiesto que el periódico con un tono más negativo, La Razón, focalizó esa negatividad hacia el tema sanitario, con un $46,7 \%$ de sus portadas, mientras que los otros dos que destacaron se orientaron hacia la Política, tanto ABC $(43,3 \%)$ como El Mundo (33,3\%). El País registró el menor porcentaje de portadas sobre la cuestión Política $(16,7 \%)$, incidiendo en Sanidad (40\%), Economía (16,7\%), Empleo (10,0\%), Beneficios Sociales $(6,7 \%)$ e Internacional $(6,7 \%)$. Este medio llevó a cabo una menor cobertura de la cuestión más crítica para el Gobierno, focalizándose en las políticas que repercutían en el bienestar de los ciudadanos en términos de salud, empleo o ayudas económicas, utilizando el frame de Seguridad detectado por Singh et al. (2020), cuyo objetivo es minimizar en el público la preocupación por los efectos de la enfermedad. Los periódicos de propiedad catalana mostraron un comportamiento dispar, ya que El Periódico mostró 
una iniciativa notablemente superior a la media en el tema Sanidad (43,3\% de sus portadas), mientras que La Vanguardia centró sus esfuerzos en Economía (33,3\%), utilizando en este caso el frame de la Consecuencia (Singh et al., 2020) al resaltar los efectos devastadores de la pandemia sobre la economía. El diferente enfoque empleado por los medios tiene su explicación en el estudio de Cook (1998), que indica que los medios funcionan como organizaciones políticas, seleccionando una variedad de posibles noticias y fuentes, y llevando a menudo a los actores políticos hacia acciones que anticipan la agenda y la naturaleza de las mismas.

Para reducir la incertidumbre en una crisis sanitaria, los líderes políticos necesitan el apoyo de los medios de comunicación para aportar una explicación creíble del acontecimiento, proporcionar orientación, infundir esperanza, mostrar empatía y sugerir que se mantiene el control de la situación (You y Ju, 2019). El framing sanitario es común en etapas posteriores a la superación de la crisis sanitaria, pero no en las etapas previas, en las que el riesgo para la salud, los contratiempos sociales que se derivan y la cuestión política son enfoques destacados (Pan y Meng, 2016).

El análisis de los conceptos redundantes en el discurso de los titulares de las portadas (Figura 3), hizo aún más específicos estos temas, en tanto que Sanidad se orientó hacia los términos "virus", "coronavirus" y "Covid" de forma mayoritaria, en vez de hacia la labor de "sanidad, hospitales, médicos y sanitarios". Los temas sanitarios buscaban mayoritariamente dar respuesta a los interrogantes respecto a la enfermedad, resaltando en este caso el frame de la Incertidumbre y el de las Nuevas Evidencias que emergen en situaciones de crisis sanitaria (Singh et al., 2020). En segundo lugar, destacaron con igual presencia el actor institucional "Gobierno" y el Presidente del mismo, Pedro Sánchez. El resto de conceptos presentes en los titulares principales de las portadas estuvieron relacionados con el cierre del país y el confinamiento, España, el Estado de Alarma y la crisis derivada. Hay que considerar que el término "millones" es compartido en titulares de diversa índole en relación a la crisis del coronavirus, refiriéndose a millones de afectados, de mascarillas necesarias, de pérdidas en Bolsa o de desempleados.

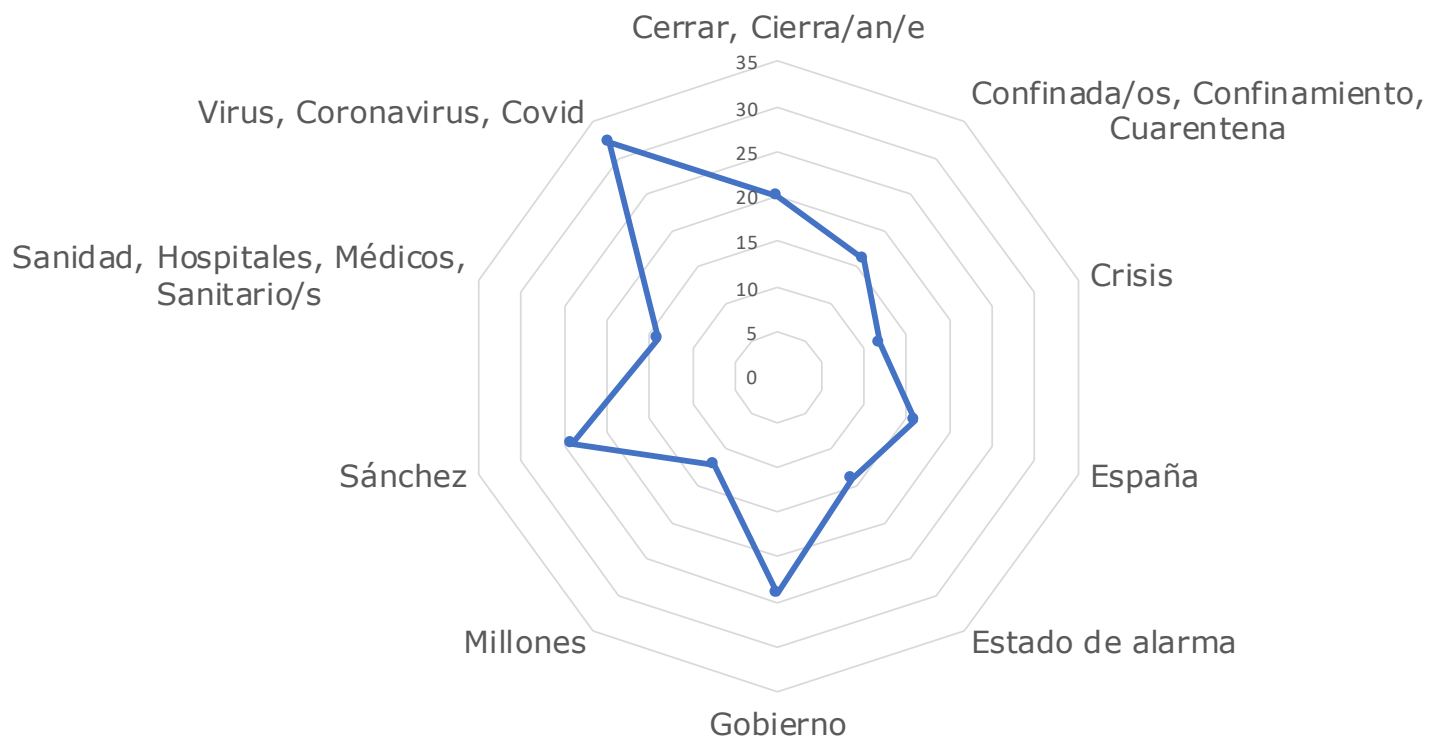

Figura 3: Conceptos redundantes en el discurso de los titulares de las portadas de los periódicos.

Fuente: Elaboración propia.

Los actores informativos presentes en los titulares de las portadas de los periódicos (Figura 4) 
estuvieron relacionados con los temas principales, destacando los Institucionales/Oficiales (57,8\%), seguidos por los Económicos (15,6\%) y los Políticos (11,7\%).

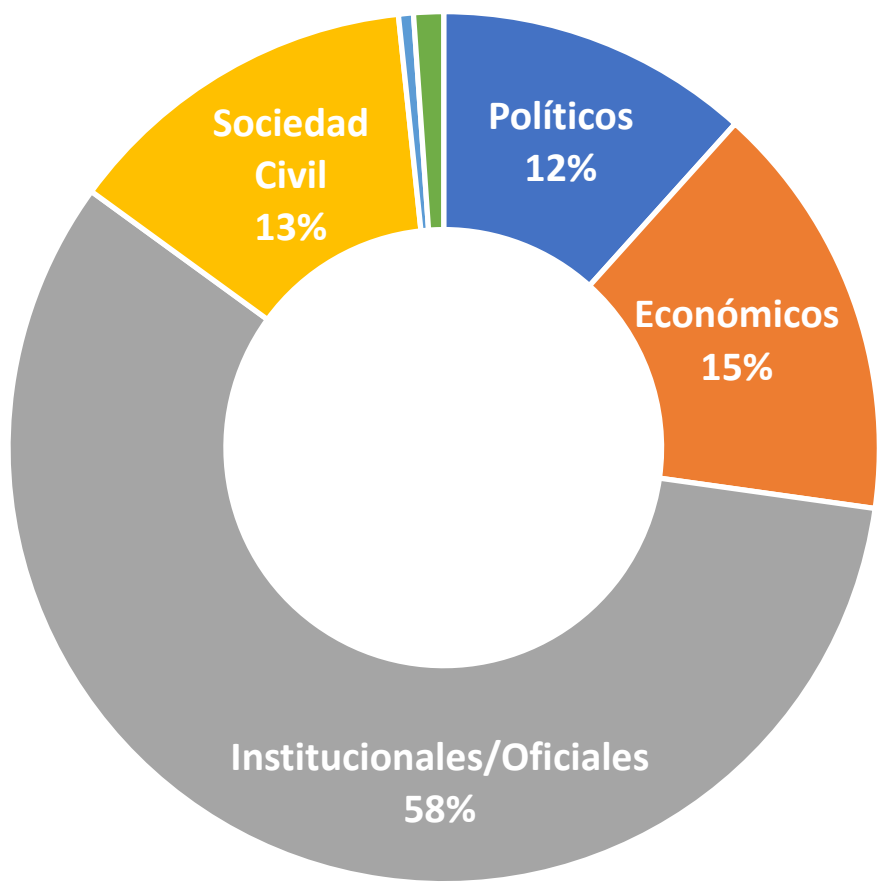

Figura 4: Actor informativo del titular en las portadas de los periódicos.

Fuente: Elaboración propia.

Tampoco en las tablas cruzadas entre las variables Periódico y Actor informativo del titular se identificó una relación de dependencia, con un moderado coeficiente de contingencia de 0,385 y una significación de $p=0,179$. Los tres periódicos que ofrecían mayor porcentaje de portadas con un tono negativo son también los tres que ofrecieron más titulares en los que los protagonistas son políticos (ABC, 26,7\%; La Razón, 16,7\%; El Mundo, 16,7\%), aunque mayoritariamente todos los periódicos optan por una figura Institucional/Oficial antes que la personalización del Político. Encabezan la Vanguardia, El Mundo (66,7\%) y El País (60,0\%). La Vanguardia destaca por el mayor registro en cuanto a actores económicos $(23,3 \%)$ y El Periódico, por la representación de la Sociedad Civil $(23,3 \%)$. El caso de El Periódico está en línea con investigaciones anteriores, que pusieron de manifiesto su intención de diferenciarse del resto de cabeceras nacionales por el protagonismo de determinados temas que posibilitan incrementar las interacciones alcanzadas con sus públicos, como, por ejemplo, el feminismo (Mañas-Viniegra, López-Cepeda y Sierra-Sánchez, 2019).

La tabla cruzada que observa el Tema del titular y el Actor informativo del mismo mostró una elevada relación de dependencia $(C=0,815)$ de forma significativa $(p=\leq 0,001)$. Cuando el tema del titular fue Política, determinó que el actor del titular también fuera Político $(36,2 \%)$ o Institucional (59,6\%), de igual modo que la Economía determinó un actor de Economía (51,4\%), o Institucional (45,9\%); Bienestar Social condicionó un actor Institucional o de Sociedad Civil (50\% en cada caso); Sanidad, un actor Institucional (68,3\%) o de Sociedad Civil (27,0\%); o Unión Europea o Monarquía, correlacionados con un actor Institucional en todos los casos $(100,0 \%)$, existiendo, por tanto, coherencia en los resultados. 
De manera contradictoria con los titulares examinados, los periódicos optaron por dar protagonismo en las fotografías (Figura 5) a la Sociedad Civil $(49,4 \%)$ por delante de los Políticos $(18,3 \%)$ o las Institucionales/Oficiales $(6,7 \%)$, siendo relevante que en el $20,6 \%$ de las portadas no existiese una fotografía vinculada al titular de la noticia principal, lo que evidencia una reivindicación de los propios periódicos del protagonismo de la información sobre cualquier otro elemento visual o narrativo.

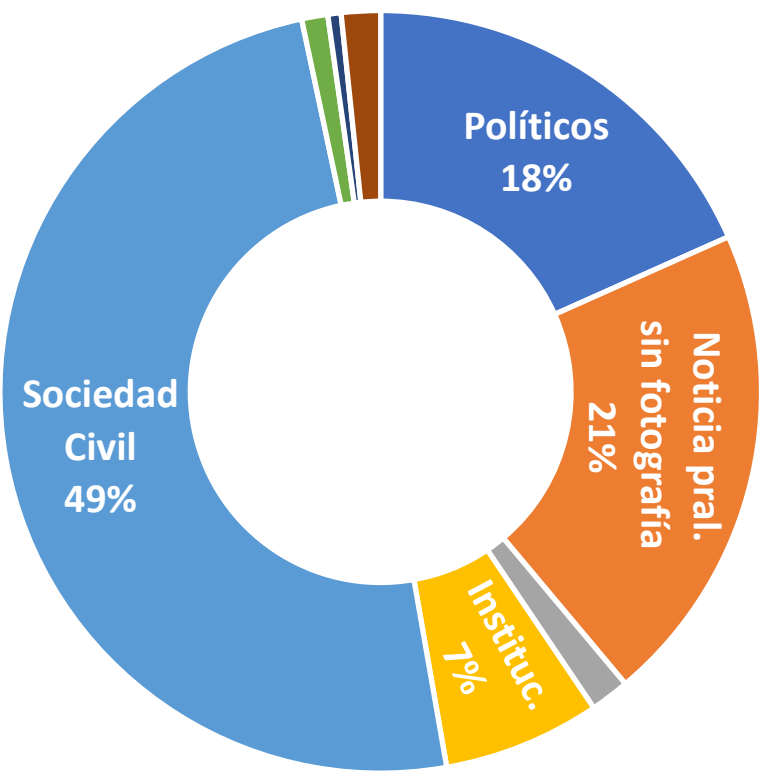

Figura 5: Actor informativo de la fotografía del titular en portada de los periódicos.

Fuente: Elaboración propia.

En esta cuestión, las diferencias fueron estadísticamente significativas $(p=\leq 0,001)$ entre los periódicos estudiados, existiendo una relación de dependencia entre las cabeceras y el tipo de Actor informativo en la fotografía vinculada al titular principal (Tabla 3). El País (43,3\%) y El Mundo $(40,0 \%)$ destacaron por presentar el doble de portadas sin fotografía asociada al titular principal con respecto al total de periódicos considerados. Los periódicos que empleaban más el tono negativo, ABC y La Razón, fueron los que más utilizaron en la fotografía del titular a los Políticos (30,0\%) y los dos periódicos catalanes utilizaron mayoritariamente las fotografías para dar protagonismo a la Sociedad Civil (El Periódico, 83,3\%; La Vanguardia, 63,3\%).

Tabla 4. Tabla cruzada Periódico/Actor informativo de la fotografía.

\begin{tabular}{|c|c|c|c|c|c|c|c|c|}
\hline Periódico & Políticos & $\begin{array}{c}\text { No } \\
\text { fotografía }\end{array}$ & $\begin{array}{c}\text { Reli- } \\
\text { giosos }\end{array}$ & $\begin{array}{c}\text { Institu- } \\
\text { cionales }\end{array}$ & $\begin{array}{c}\text { Sociedad } \\
\text { civil }\end{array}$ & $\begin{array}{c}\text { Cultu- } \\
\text { rales }\end{array}$ & $\begin{array}{c}\text { Medios } \\
\text { comunic. }\end{array}$ & $\begin{array}{c}\text { Econó- } \\
\text { micos }\end{array}$ \\
\hline ABC & $30,0 \%$ & $0,0 \%$ & $0,0 \%$ & $26,7 \%$ & $33,3 \%$ & $3,3 \%$ & $3,3 \%$ & $3,3 \%$ \\
\hline El Mundo & $13,3 \%$ & $40,0 \%$ & $0,0 \%$ & $0,0 \%$ & $46,7 \%$ & $0,0 \%$ & $0,0 \%$ & $0,0 \%$ \\
\hline El País & $23,3 \%$ & $43,3 \%$ & $0,0 \%$ & $0,0 \%$ & $33,3 \%$ & $0,0 \%$ & $0,0 \%$ & $0,0 \%$ \\
\hline La Razón & $30,0 \%$ & $23,3 \%$ & $3,3 \%$ & $6,7 \%$ & $36,7 \%$ & $0,0 \%$ & $0,0 \%$ & $0,0 \%$ \\
\hline La Vanguardia & $10,0 \%$ & $16,7 \%$ & $3,3 \%$ & $3,3 \%$ & $63,3 \%$ & $3,3 \%$ & $0,0 \%$ & $0,0 \%$ \\
\hline El Periódico & $3,3 \%$ & $0,0 \%$ & $3,3 \%$ & $3,3 \%$ & $83,3 \%$ & $0,0 \%$ & $0,0 \%$ & $6,7 \%$ \\
\hline Total & $18,3 \%$ & $20,6 \%$ & $1,7 \%$ & $6,7 \%$ & $49,4 \%$ & $1,1 \%$ & $0,6 \%$ & $1,7 \%$ \\
\hline
\end{tabular}

Fuente: Elaboración propia. 
Las fotografías de los actores políticos que acompañaron a los titulares (Figura 6) se concentraron en el Gobierno, ya fuese su Presidente Pedro Sánchez solo o con los miembros de su Gobierno, o sus Ministros, siendo casi irrelevante la aparición de los políticos de la oposición, lo que refuerza la idea de que el tono negativo en los titulares se direcciona hacia la gestión del Gobierno en la crisis del coronavirus Covid-19, reforzando el papel protagónico del frame de Conflicto detectado por Singh et al. (2020) en su estudio sobre la cobertura mediática de las pandemias.

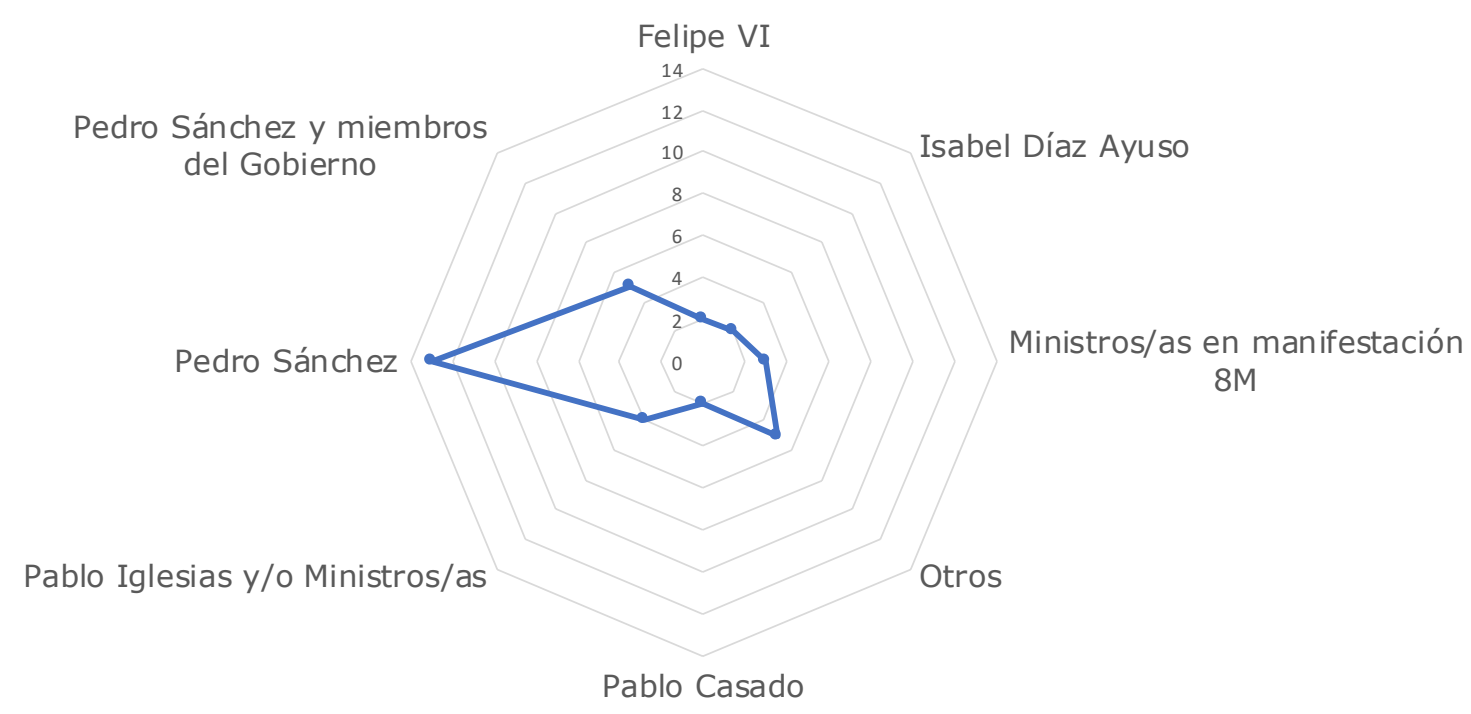

Figura 6: Actores políticos en la fotografía del titular en las portadas de los periódicos.

Fuente: Elaboración propia.

Con un elevado Coeficiente de Contingencia $(0,755)$ y una relación de dependencia significativa entre las variables Tema del titular y Actor informativo de la fotografía $(p=\leq 0,001)$, destaca que el Tema Bienestar Social estuviera más asociado a un Actor informativo en la fotografía de Política $(50,0 \%)$, cifra más elevada que la obtenida por el propio tema Política $(31,9 \%)$, que a su vez estuvo más relacionado con la aparición de la Sociedad Civil (53,2\%). Los temas que suprimieron la fotografía asociada de forma clara fueron Monarquía (100,0\%), Empleo (54,5\%), Unión Europea $(50,0 \%)$ y Economía $(37,8 \%)$. Los temas que se relacionaron de manera intensa con el Actor informativo de la fotografía Sociedad Civil fueron Internacional (75,0\%), Sanidad (54,0\%) y Política $(53,2 \%)$.

Aunque todos los periódicos concentraron el espacio informativo del titular en España sin diferencias significativas $(p=0,113)$, con un total del $85,0 \%$ de las portadas, esta concentración fue más notable en los periódicos cuyo tono del titular era negativo: La Razón (96,7\%), ABC y El Mundo (93,3\%). El País, La Vanguardia y El Periódico apostaron por un espacio Internacional/Global $(10,0 \%)$, al menos, europeo (16,7\% El País y La Vanguardia; 10,0\% El Periódico).

La tabla cruzada entre el Tema y el Espacio informativo del titular, con un Coeficiente de Contingencia medio $(0,584)$ y una relación de dependencia con diferencias significativas entre las variables $(p=\leq 0,001)$, mostró que los temas de Bienestar Social, Monarquía, Empleo, Cultura, Poder Judicial e Industria se refirieron en todos los casos (100,0\%) a España, mientras que, de forma mayoritaria, Unión Europea se centró en ese mismo territorio $(100,00 \%)$ e Internacional se repartió entre Unión Europea (62,5\%), Internacional (25,0\%) y Asia (12,5\%). 
En definitiva, se aprecia en el análisis la presencia de los seis encuadres Consecuencia, Incertidumbre, Acción, Seguridad, Conflicto y Nuevas Evidencias identificados en la cobertura informativa de otras epidemias en medios impresos (Singh et al., 2020).

\section{Conclusiones}

El análisis longitudinal realizado permite describir con detalle la agenda mediática de portada predominante en la prensa española de referencia con respecto a la crisis sanitaria del Covid-19.

Ha primado el tono negativo en los titulares de las cabeceras nacionales objeto de análisis. A nivel de contenido, ese tono catastrofista hacía referencia fundamentalmente a la gestión del Gobierno, a la ansiedad, incertidumbre y estado de depresión psicológica y económica. Los diarios más alejados ideológicamente del actual Gobierno han presentado los titulares más negativos.

Los temas recogidos en el titular condicionan el tono empleado en el mismo. Y es ahí, en la interpretación del hecho, donde se pone de manifiesto la ideología política del diario. Se ha podido comprobar cómo cuanto más restrictivas eran las medidas planteadas por el Gobierno (Estado de alarma y sucesivas prórrogas), más positivos eran los mensajes que los diarios dirigían a la población a través de sus portadas.

La pandemia del Covid-19 se ha enfocado en las portadas de los diarios generalistas españoles en tres temáticas fundamentalmente, a saber, por orden de importancia; sanidad, política y economía. La primera de ellas, está enfocada fundamentalmente hacia los datos de la expansión y medidas de contención y prevención. La política está centrada en las medidas legislativas acordadas por el Gobierno, así como por la parte ejecutiva de gestión de éste para dotar de recursos al sistema sanitario público español. Y, en último lugar, la temática económica hace referencia a las medidas de apoyo al tejido productivo del país.

En cuanto al análisis visual de las portadas, la prensa generalista española, ha primado en sus fotos como actor informativo a la sociedad civil, representada en médicos, enfermeros, Cuerpos y Fuerzas de Seguridad del Estado, voluntarios y trabajadores de actividades esenciales. Los temas que más se relacionan con el actor sociedad civil son internacional, sociedad y política.

Son precisamente aquellos diarios que han empleado un tono más negativo en sus titulares los que han utilizado un mayor número de fotografías de políticos para reforzar sus titulares. Fundamentalmente, han empleado fotos del Presidente del Gobierno y de sus Ministros.

\section{Bibliografía}

Ahorsu, D. K.; Lin, C. Y.; Imani, V.; Saffari, M.; Griffiths, M. D. y Pakpour, A. H. (2020). The Fear of COVID-19 Scale: Development and Initial Validation. International Journal of Mental Health and Addiction [en prensa]. https://doi.org/10.1007/s11469-020-00270-8

AIMC (2020). Entrega de resultados EGM $1^{a}$ ola 2020. AIMC. http://reporting.aimc.es/index.html\#/main/diarios

Alvarado, H. (2008). El rostro de la prensa de calidad. La información internacional desde la portada de los grandes diarios europeos. Textual \& Visual Media, 1, 21-47. http://textualvisualmedia.com/index.php/txtvmedia/article/view/1/7 
Álvarez-Gálvez, J. (2012). Modelos teóricos sobre los efectos de los medios de comunicación de masas (Documento de trabajo $\mathrm{n}^{\circ}$ 2). Universidad Complutense de Madrid. https://eprints.ucm.es/45089/

Ardèvol-Abreu, A. (2015). Framing o teoría del encuadre en comunicación. Orígenes, desarrollo y panorama actual en España. Revista Latina de Comunicación Social, 70, 423-450. https://doi.org/10.4185/RLCS-2015-1053

Bardin, L. (1986). El análisis de contenido. Akal.

Brown, P. (2020). Studying COVID-19 in light of critical approaches to risk and uncertainty: research pathways, conceptual tools, and some magic from Mary Douglas. Health Risk \& Society, 22(1), 1-14. https://doi.org/10.1080/13698575.2020.1745508

Cinelli, M.; Quattrociocchi, W.; Galeazzi, A.; Valensise, C.; Brugnoli, E.; Schmidt, A. L.; Zola, P.; Zollo, F. y Sacala, A. (2020). The covid-19 social media infodemic. arXiv, 2003.05004 [en prensa]. https://arxiv.org/pdf/2003.05004.pdf

Chong, D. y Druckman, J. (2007). Framing theory. Annual Review of Political Science, 10, 103-126. https://doi.org/10.1146/annurev.polisci.10.072805.103054

Cohen, B. (1964). The Press and Foreign Policy. American Political Science Review, 58(2), 470-471. https://doi.org/10.1017/S0003055400289284

Cook, T. (1998). Governing with the news: The news media as a political institution. University of Chicago Press.

Costa-Sánchez, C.; López-García, X. (2020). Comunicación y crisis del coronavirus en España. Primeras lecciones. El profesional de la información, 29(3), 290-304. https://doi.org/10.3145/epi.2020.may.04

Cowper, A. (2020). Covid-19: are we getting the communications right? BMJ, 368, m919. https://doi.org/10.1136/bmj.m919

Danielson, W. A. y Lasorsa, D. L. (1997). Perceptions of Social Change: 100 Years of Front-Page Content in the New York Times and the Los Angeles Times. En: C. W. Roberts (Ed.), Text Analysis for the Social Sciences: Methods for Drawing Statistical Inferences from Texts and Transcripts (pp. 103-115). Erlbaum.

Davara-Torrego, F. J.; López-Raso, P.; Martínez-Fresneda, H. y Sánchez-Rodríguez, G. (2004). España en portada. Análisis de las primeras páginas de los diarios nacionales y su influencia en la sociedad. Fragua.

Entman, R. M. (1993). Framing: Toward clarification of a fractured paradigm. Journal of Communication 43(4), 51-58. https://doi.org/10.1111/j.1460-2466.1993.tb01304.x

Erbring, L.; Goldenberg, E. N. y Miller, A. H. (1980). Front-Page News and Real-World Cues: A New Look at Agenda-Setting by the Media. American Journal of Political Science, 24(1), 16-49. https://doi.org/10.2307/2110923 
Fenoll, V. y Rodríguez-Ballesteros, P. (2017). Análisis automatizado de encuadres mediáticos. Cobertura en prensa del debate 7D 2015: el debate decisivo. El profesional de la Información, 26(4), 630-640. https://doi.org/10.3145/epi.2017.jul.07

Gamson, W. y Modigliani, A. (1989). Media discourse and public opinion on nuclear power: a constructionist approach. American Journal of Sociology, 95(1), 1-37. https://doi.org/10.1086/229213

García-Ferrando, M.; Ibáñez, J. y Alvira, F. (1986). El análisis de la realidad social. Métodos y técnicas de investigación. Alianza.

Garrett, L. (2020). COVID-19: the medium is the message. The Lancet, 395(10228), 942-943. https://doi.org/10.1016/S0140-6736(20)30600-0

Garrett, L. (2001). Understanding media's response to epidemics. Public Health Reports, 116(2), 87. https://doi.org/10.1016/S0033-3549(04)50149-8

Gibson, D. R. (2011). All the News That Fits to Print: Desk Competition From Front- Page Space at the New York Times. Sociological Forum, 26(2), 287-305. https://doi.org/10.1111/j.15737861.2011.01241.x

Glik, D. C. (2007). Risk communication for public health emergencies. Annual Review of Public Health, 28, 33-54. https://doi.org/10.1146/annurev.publhealth.28.021406.144123

Idoiaga, N.; Gil-de-Montes, L. y Valencia, J. F. (2016). Communication and representation of risk in health crises: the influence of framing and group identity. Revista de Psicología Social, 31(1), 5974. https://doi.org/10.1080/02134748.2015.1101313

León León, M. E., Linares Herrera, M. P. y Junco Martínez, F. (2018). Oportunidades y desafíos relevantes de la educación para la comunicación ciudadana como concreción de una agenda de desarrollo local sostenible. Revista de Ciencias de la Comunicación e Información, 23(2), 15-25. http://doi.org/10.35742/rcci.2018.23(2).15-25

Li, W. G., Liao, J., Li, Q. Y., Baskota, M., Wang, X. M., Tang, Y. Y., .. \& Liu, E. M. (2020). Public health education for parents during the outbreak of COVID-19: a rapid review. Annals of Translational Medicine, 8(10), e628. https://doi.org/10.21037/atm-20-3312

López-Aranguren, E. (1989). El análisis de contenido. En: M. García-Ferrando (Coord.), El análisis de la realidad social: Métodos y técnicas de investigación (pp. 594-616). Alianza.

López-Rabadán, P. (2010). Nuevas vías para el estudio del framing periodístico. La noción de estrategia de encuadre. Estudios sobre el Mensaje Periodístico, 16, 235-258. https://revistas.ucm.es/index.php/ESMP/article/view/ESMP1010110235A

López-Rabadán, P. y Casero-Ripollés, A. (2012). La evolución de la agenda mediática española (1980-2010). Un análisis longitudinal de la portada de la prensa de referencia. Revista Latina de comunicación social, 67, 470-493. https://doi.org/10.4185/RLCS-2012-964 
Mañas-Viniegra, L.; López-Cepeda, I. y Sierra-Sánchez, J. (2019). Consumo e interacciones de las noticias publicadas en redes sociales por los diarios españoles y europeos. Trípodos, 45, 135-156. http://www.tripodos.com/index.php/Facultat_Comunicacio_Blanquerna/article/view/690

Masip, P.; Aran-Ramspott, S.; Ruiz-Caballero, C.; Suau, J.; Almenar, E.; Puertas-Graell, D. (2020).

Consumo informativo y cobertura mediática durante el confinamiento por el Covid-19: sobreinformación, sesgo ideológico y sensacionalismo. El profesional de la información, 29(3), 290-312. https://doi.org/10.3145/epi.2020.may.12

McCombs, K. y Shanahan, J. (1999). Telling stories about global climate change: Measuring the impact of narratives on issue cycles. Communication Research, 26(1), 30-57. https://doi.org/10.1177/009365099026001003

McCombs, M. y Shaw, D. L. (1972). The agenda-setting function of the mass media. Public Opinion Quarterly, 36, 176-185. www.jstor.org/stable/2747787

McCombs, M.; Llamas, J. P.; López-Escobar, E. y Rey, F. (1997). Candidate images in Spanish elections: second level agenda-setting effects. Journalism and Mass Communication Quarterly, 74(4), 703-717. https://doi.org/10.1177/107769909707400404

McGuire, W. J. (1985). Attitudes and attitude change. En: G. Lindzey y E. Aronson (Coords.), Handbook of social psychology (pp. 233-346). Random House.

Nisbet, M. C.; Brossard, D. y Kroepsch, A. (2003). Framing science: The stem cell controversy in an age of press/politics. Harvard International Journal of Press/Politics, 8(2), 36-70. https://doi.org/10.1177/1081180X02251047

OJD (2020). Auditoría de medios impresos. https://extranet.introl.es/web_ojd/misc/errores/404.aspx?aspxerrorpath=/web_ojd/DatosMensuales ojd.aspx

Pan, P. L. y Meng, J. (2016). Media Frames across Stages of Health Crisis: A Crisis Management Approach to News Coverage of Flu Pandemic. Journal of Contingencies and Crisis Management, 24(2), 95-106. https://doi.org/10.1111/1468-5973.12105

Piñuel, J. L. y Gaitán, J. A. (1995). Metodología general. Síntesis.

Ratzan, S.; Gostin, L.; Meshkati, N.; Rabin, K. y Parker, R. (2020). COVID-19: An Urgent Call for Coordinated, Trusted Sources to Tell Everyone What They Need to Know and Do. NAM Perspectives. https://doi.org/10.31478/202003a

Rogers, E. y Dearing, J. (1994). Agenda-Setting Research: Where has it been, where is it going? En: D. Graber (Ed.), Media Power in Politics. Congressional Quarterly.

Rossmann, C.; Meyer, L. y Schulz, P. J. (2018). The Mediated Amplification of a Crisis: Communicating the A/H1N1 Pandemic in Press Releases and Press Coverage in Europe. Risk Analysis, 28(2), 357-375. https://doi.org/10.1111/risa.12841 
Sábada-Garraza, T. (2004). Enfoques periodísticos y marcos de participación política. Una aproximación conjunta a la teoría del encuadre. Política y sociedad, 41(1), 65-76. https://revistas.ucm.es/index.php/POSO/article/view/POSO0404130065A

Salaverría, R.; Buslón, N.; López-Pan, F.; León, B.; López-Goñi, I.; Erviti, M.C. (2020). Desinformación en tiempos de pandemia: tipología de los bulos sobre la Covid-19. El profesional de la información, 29(3), 290-315. https://doi.org/10.3145/epi.2020.may.15

Scheufele, D. A. (1999): Framing as a theory of media effects. Journal of Communication, 49(1), 103-122. https://doi.org/10.1111/j.1460-2466.1999.tb02784.x

Scheufele, D. A. y Tewksbury, D. (2007). Framing, agenda setting, and priming: The evolution of three media effects models. Journal of Communication, 57(1), 9-20. https://doi.org/10.1111/j.0021-9916.2007.00326.x

Shah D.; Watts, M.; Domke, D. y Fan, D. (2002). News framing and cueing of issue regimes: explaining Clinton's public approval in spite of scandal. Public Opinion Quaterly, 66(3), 339-70. https://doi.org/10.1086/341396

Singh, L.; Bansal, S.; Bode, L.; Budak, C.; Chi, G.; Kawintiranon, K.; Padden, C.; Vanarsdall, R.; Vraga, E. y Wang. Y. (2020). A first look at COVID-19 information and misinformation sharing on Twitter. arXiv [en prensa], 2003.13907. https://arxiv.org/pdf/2003.13907.pdf

Stein, M. B. (2020). COVID-19 and Anxiety and Depression in 2020. Depression and Anxiety, 37(4), 302-302. https://doi.org/10.1002/da.23014

Tankard, J. (2001). The Empirical Approach to the Study of Media Framing. En: S. D. Reese; O. H. Gandy y A. E. Grant (Eds.), Framing Public Life: Perspectives on Media and our Understanding of the Social World (pp. 95-106). Lawrence Erlbaum Associates.

Thomas, T. L.; Kannaley, K.; Friedman, D. B.; Tanner, A. H.; Brandt, H. M. y Spencer, S. M. (2016). Media Coverage of the 2014 West Virginia Elk River Chemical Spill: A Mixed-Methods Study Examining News Coverage of a Public Health Disaster. Science Communication, 38(5), 574-600. https://doi.org/10.1177/1075547016662656

Tian, Y. y Stewart, C. (2005). Framing the SARS Crisis: A Computer-Assisted Text Analysis of CNN and BBC Online News Reports of SARS. Asian Journal of Communication, 15(3), 289-301. https://doi.org/10.1080/01292980500261605

Torales, J.; O'Higgins, M.; Castaldelli-Maia, J. M. y Ventriglio, A. (2020). The outbreak of COVID19 coronavirus and its impact on global mental health. International Journal of Social Psychiatry [en prensa], e0020764020915212. https://doi.org/10.1177/0020764020915212

Tuchman, G. (1978). Making News. Free Press.

Vander-Zanden, J. W. (1986). Manual de Psicología Social. Paidós. 
Vicente-Mariño, M. y López-Rabadán, P. (2009). Resultados actuales de la investigación sobre framing: sólido avance internacional y arranque de la especialidad en España. Zer, 14(26), $1137-$ 1102. https://www.ehu.eus/ojs/index.php/Zer/article/view/2750/2364

Wallis, P. y Nerlich, B. (2005). Disease metaphors in new epidemics: the UK media framing of the 2003 SARS epidemic. Social Science \& Medicine, 60(11), 2629-2639. https://doi.org/10.1016/j.socscimed.2004.11.031

Weaver, D. H. (2007). Toughts on agenda-setting, framing and priming. Journal of Communication, 57, 142-147. https://doi.org/10.1111/j.1460-2466.2006.00333.x

You, M. y Ju, Y. (2019). Salience of public leaders' "meaning making" in news coverage of a health crisis. Journal of Contingencies and Crisis Management, 27(4), 400-405. https://doi.org/10.1111/1468-5973.12259

\section{AUTOR/ES:}

\section{Patricia Núñez-Gómez}

Universidad Complutense de Madrid

Patricia-Núñez Gómez es Doctora en Comunicación Audiovisual y Publicidad, Profesora Titular y Directora del Departamento de Ciencias de la Comunicación Aplicada de la Universidad Complutense de Madrid. También es Directora de la Cátedra Extraordinaria de Marketing y Comunicación para la Infancia y la Adolescencia de la misma Universidad.

pnunezgo@ucm.es

\section{Índice H: 14}

Orcid ID: https://orcid.org/0000-0002-0073-2020

Google Scholar: https://scholar.google.es/citations?user=hqiRHYsAAAAJ\&hl=es\&oi=ao

ResearchGate: https://www.researchgate.net/profile/Patricia_Gomez17

Scopus ID: $\underline{\text { https: } / / \text { www.scopus.com/authid/detail.uri?authorId=55580401900 }}$

Academia.edu: http://independent.academia.edu/PatriciaNúñezGómez

\section{Natalia Abuín Vences}

Universidad Complutense de Madrid

Natalia Abuín-Vences es Doctora en Comunicación Audiovisual y Publicidad por la Universidad Complutense de Madrid. Actualmente es profesora de Cultura de las Organizaciones en el Departamento de Ciencias de la Comunicación Aplicada de la UCM. En 2015 fue miembro del Comité de Innovación de Ofertas Formativas Digitales ANECA-SETSI. Ha participado en diversos programas y proyectos de investigación de índole nacional (Plan Nacional I+D+i), autonómico (Comunidad de Madrid) e internacional (a través de la European Communication Research and Education Association).

nabuinve@ucm.es

Índice H: 12

Orcid ID: https://orcid.org/0000-0002-4153-9390

Google Scholar: https://scholar.google.es/citations?user=qBhjgBEAAAAJ\&hl=es\&oi=ao

ResearchGate: https://www.researchgate.net/profile/Natalia Abuin

Scopus ID: https://www.scopus.com/authid/detail.uri?authorId=56034032800

Academia.edu: https://independent.academia.edu/NataliaAbu\%C3\%ADnVences 


\section{Javier Sierra-Sánchez}

Universidad Complutense de Madrid

Javier Sierra-Sánchez es Doctor en Ciencias de la Información por la Universidad Complutense de Madrid (UCM) y licenciado en Comunicación Audiovisual y Periodismo por la misma universidad. Master oficial en Marketing y Comunicación Corporativa por la Universidad San Jorge. Experto en RRPP Internacionales por la UCM. Experto en Protocolo y Ceremonial del Estado e Internacional por la Universidad de Oviedo y la Escuela Diplomática de Madrid. Actualmente ejerce docencia como profesor contratado doctor en la Universidad Complutense de Madrid.

javiersierrasanchez@pdi.ucm.es

\section{Índice H: 11}

Orcid ID: https://orcid.org/0000-0001-8572-7564

Google Scholar: https://scholar.google.es/citations?user=oGqa6PgAAAAJ\&hl=es\&oi=ao

ResearchGate: https://www.researchgate.net/profile/Javier_Sierra5

Scopus ID: https://www.scopus.com/authid/detail.uri?authorId=55579423600

Academia.edu: https://ucm.academia.edu/JavierSierraSánchez

\section{Luis Mañas-Viniegra}

Universidad Complutense de Madrid

Luis Mañas-Viniegra es Doctor en Comunicación Audiovisual y Publicidad, profesor ayudante doctor en la Universidad Complutense de Madrid y miembro del Grupo de Investigación Complutense Gestión de Marca y Comunicación Integrada. Sus principales líneas de investigación son la gestión de intangibles en Comunicación y la aplicación de las nuevas tecnologías a la innovación docente.

lmanas@ucm.es

Indice H: 6

Orcid ID: https://orcid.org/0000-0001-9129-5673

Google Scholar: https://scholar.google.es/citations?user=UsVJTKUAAAAJ\&hl=es

ResearchGate: https://www.researchgate.net/profile/Luis_Manas-Viniegra

Scopus ID: https://www.scopus.com/authid/detail.uri?authorId=57197747570

Publons: https://publons.com/researcher/1396662/luis-manas-viniegra/

Academia.edu: https://ucm.academia.edu/LuisMañasViniegra 